\title{
INCISIONAL HERNIA AT THE INSERTION SITE OF THE LAPAROSCOPIC TROCAR: CASE REPORT AND REVIEW OF THE LITERATURE
}

\author{
Frederico Teixeira, Jin Hwan Yoo and Aldo Junqueira Rodrigues Júnior
}

TEIXEIRA F et al. - Incisional hernia at the insertion site of the laparoscopic trocar: case report and review of the literature. Rev. Hosp. Clín. Fac. Med. S. Paulo 58(4):219-222 2003.

Laparoscopic operations offer a myriad of advantages resulting in a rapid postoperative recovery. Incisional hernia is an uncommon cause of morbidity in operative procedures performed by laparoscopic access, and the diagnosis may not be easily made.

In our service we identified 2 patients with incisional hernia the site of trocar insertion. The records of these 2 cases were reviewed. We report on these 2 cases and present a review of the literature.

DESCRIPTORS: Hernia. Incisional hernia. Laparoscopy. Cholecystectomy. Cholelithiasis.

Since the accomplishment of the first laparoscopic cholecystectomy by Philipe Mouret in 1987 in France, laparoscopic surgery has quickly developed, becoming in some cases the gold standard procedure as the preferred mode of access to the abdominal cavity ${ }^{1,2}$.

The benefits of video-assisted laparoscopy include minimal risk to the safety of the patient without compromising the success of the intervention, less postoperative pain, shorter hospitalization stay, rapid return to habitual activities, and better aesthetic effect of the incisions ${ }^{2}$. However, despite these advantages, laparoscopic procedures are not exempt from complications.

We report on the cases of 2 patients who developed incisional hernias at the trocar insertion sites that were produced during the laparoscopic treatment of symptomatic cholelithiasis; we also report relevant points found in the medical literature regarding prevention of this complication.

\section{Patients}

Case 1: GA, 71 year old, female, who had a clinical and ultrasound diagnosis of symptomatic cholelithiasis. In February 1998, she underwent video-assisted laparoscopic cholecystectomy, in which $11 \mathrm{~mm}$ trocars had been inserted into the umbilical scar and epigastric region. Both the aponeurotic defects were closed with simple sutures of Poliglactin 910. Hospital discharge occurred on the first postoperative day (PD). On the $10^{\text {th }} \mathrm{PD}$, she presented a painful and reducible bulging in the surgical wound of the epigastric region, without signs or symptoms of intestinal obstruction. Incisional hernia (IH) was diagnosed, and she underwent local exploratory surgery, with reduction of the omentum that was entrapped in the fascial defect by transverse closure of the aponeurotic edges with Poliglactin 910 stitches. The evolution was without complications.

From the General Surgery Service, Hospital das Clínicas, Faculty of Medicine, University of São Paulo - São Paulo/SP, Brazil. Received for publication on September 27, 2002.
Case 2: MTA, 40 year old, female, in late postoperative stage after laparoscopic cholecystectomy for symptomatic cholelithiasis, in which 10 and $12 \mathrm{~mm}$ trocars had been used in the umbilical scar and epigastric regions, respectively. She developed a reducible and painless bulging in the epigastric scar after 1 year (Fig.1), which was diagnosed as IH. Local exploratory surgery disclosed entrapped omentum (Fig. 2). The defect was corrected with the union of aponeurosis edges in the transverse direction with simple stitches of Poliglactin 910, without tension. The postoperative evolution was without complications.

\section{DISCUSSION}

Complications related to the insertion of the laparoscopic trocars have stimulated an increasing number of publications $^{3,4}$. Although IH in the site of insertion of the laparoscopic trocar is an uncommon condition ${ }^{5-9}$, in our opinion, its occurrence can be reduced further.

Fear, in 1968, was the first one to describe a case of $\mathrm{IH}$ in the abdominal 
wound of laparoscopic surgery ${ }^{23}$. Subsequently, Sciff and Naftolin described 2 cases of IH, with imprisonment of small intestine in the trocar site of insertion, 3 weeks after laparoscopy ${ }^{18}$.

The post-laparoscopy incidence of IH reported in the literature is variable. We found a few reports in medical lit-

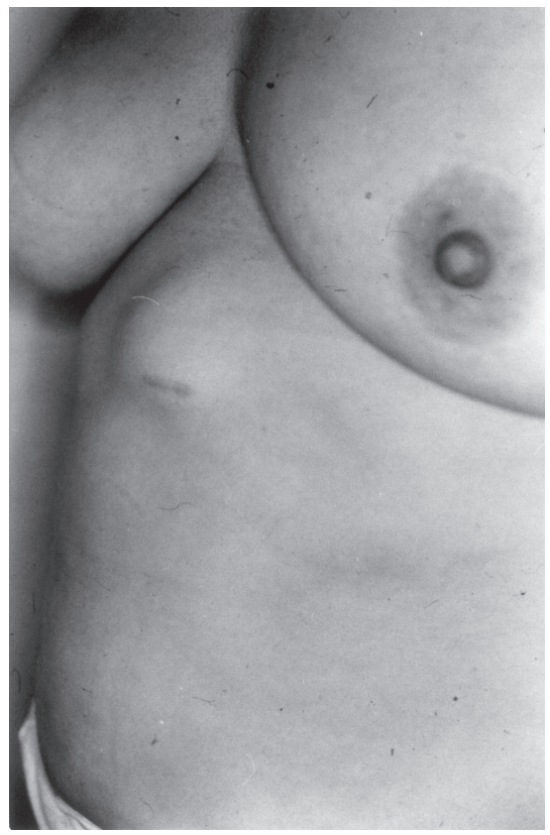

Figure 1 - Reducible painless bulging in the epigastric scar after laparoscopy.

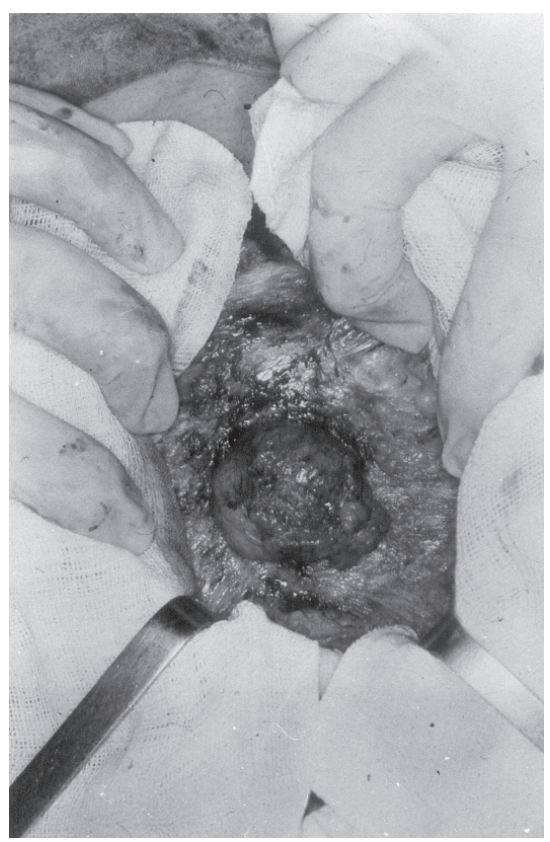

Figure 2 - Local exploration revealing incisional hernia with entrapped omentum in the aponeurotic opening. erature, with the incidence ranging from $0.02 \%$ to $1.6 \%$ (Table 1 ).

Many factors have been related to the potential development of $\mathrm{IH}$ after laparoscopic surgery, such as the number of trocars used and their diameters, the duration of the surgery, the aponeurotic defects brought about by the trocar, the insertion technique of the trocar, a pre-existing umbilical hernia, and the manner of withdrawal of the trocars.

Laparoscopic procedures that require multiple trocars are associated with a higher frequency of $\mathrm{IH}$; it is infrequent in the evolution of patients when only 2 trocars are used ${ }^{21}$. However, the use of 10,11 , and $12 \mathrm{~mm}$ trocars without doubt results in the increase of IH. Montz observed that $86.3 \%$ of the hernias included in their study had occurred with the use of trocars that were $10 \mathrm{~mm}$ or larger ${ }^{25}$.

Although rare, aponeurotic defects smaller than $10 \mathrm{~mm}$, such as those produced by a $5 \mathrm{~mm}$ trocar, can be sites of hernias, especially when the pediatric population is considered. Nakajima et al. described a case of Richter's hernia in a 6-month-old child who underwent laparoscopic fundoplication using a trocar of 5 $\mathrm{mm}^{5}$. The use of instruments such as clippers, staplers, and suction cleaners mandate the use of larger trocars; similarly, the withdrawal of the gallbladder and its calculi, lymph nodes, ovary, and cecal appendix require the dilatation of the fascial defect. In our cases, the hernias appeared where 10 and $11 \mathrm{~mm}$ trocars had been used in the epigastric region through which the gallbladder had been removed without the need for dilatation of the fascial defect. The use of trocars to anchor to the aponeurosis, called "fascial screws", can also increase the diameter of the aponeurotic fascial defect from 1 to $2 \mathrm{~mm}^{21}$. During the introduction of the trocar by the open technique, the defect in the aponeurosis can be too large in relation to the diameter of the trocar, which can indicate the use of fascial screws.

More extensive surgery or longer surgical times are also related to a higher incidence of IH. Kaddar et al. observed in a study of 3560 laparoscopies that an excessive manipulation of the trocars occurred in extensive procedures, enlarging the fascial defect even more ${ }^{24}$. However, we want to emphasize the fact that most of the reports on post-laparoscopic $\mathrm{IH}$ concern surgical and gynecological procedures such as cholecystectomies, hepatic biopsies, oophorectomies, or appendicectomies, where extended surgical time is usually not necessary, nor is extreme manipulation required for dissection ${ }^{4}$. In our cases, the cholecystectomies had been conducted within an operation time of less than 2 hours without any difficulty regarding the dissection of the structures.

Blind introduction of trocars has also been associated with IH. Fernandez-Represa et al. reported that in their series, all the patients who developed IH had trocars inserted by blind technique ${ }^{4}$. This complication results from the small incision in the skin that limits the adequate display of the aponeurosis at the moment of the abdominal wall closure.

Another related factor was reported by Azurin et al., who showed that $90 \%$ of their patients with hernias in the umbilical wound after laparoscopy had an incidental finding of a pre-existing umbilical hernia ${ }^{3}$. It is important to consider evaluating the need for use

Table 1 - Post-laparoscopy hernia incidence.

\begin{tabular}{lll}
\hline Author / Year & Cases & Incidence \\
\hline Azurin et al. / 1995 (3) & 1300 & $0.77 \%$ \\
Fernandez-Represa / 1997 (4) & 403 & $1.6 \%$ \\
Montz et al. / 1994 (25) & $4,385,000$ & $0.02 \%$ \\
\hline
\end{tabular}


of tension-free repair, and that is not an easy decision to make for surgeries with small skin incisions. Ikard described the combined repair of umbilical hernias and laparoscopic cholecystectomy. In this procedure, the hernia is reduced using a standard, non-endoscopic approach; next, a Hasson trocar is inserted into the hernia defect to establish a camera port, and the cholecystectomy is completed using an endoscopic technique; finally, the umbilical hernia is corrected ${ }^{32}$.

In addition to the factors related to the choice of the trocar and its method of introduction, there are also conditions during the withdrawal of the trocar that potentially cause IH. Whiteley mentions that during the $\mathrm{CO}_{2}$ output before the withdrawal of trocars, a pressure gradient is created between the gas in the peritoneal cavity and the atmosphere, causing the omentum or the intestine to be entrapped in the aponeurotic orifice ${ }^{33}$. The blind withdrawal of trocars after evacuating the pneumoperitoneum is a practice that must be discouraged because when removing trocars, the size of the wound becomes smaller, which adds to the pressure gradient, causing entrapment of the omentum or the intestine. Thus, the trocar must be removed under direct visualization, and the wound should be digitally explored, assuring that no bowel has been entrapped.

Hernias like the Richter's hernia, have been reported infrequently in relationship with laparoscopy ${ }^{57,19}$. In addition to the small bowel and the omen- tum, as in the case that we have reported, other organs such as the colon ${ }^{20}$ may be part of the content of the hernia.

Sometimes when strangulation of the hernia occurs, a catastrophic outcome with ischemia and necrosis of the intestinal loops may occur, requiring exploratory laparotomy and intestinal resection ${ }^{18}$. This possibility is of particular importance in laparoscopic surgeries performed in obese patients, because the thick adipose tissue can require extra effort to make the closure of the muscular defect, as well as the diagnosis of the hernia.

For diagnosis in cases where the clinical examination is not sufficient, the surgeon can make use of image tests, such as the intestinal transit or computer tomography ${ }^{9}$.

Therefore, IH at the site of introduction of the laparoscopic trocar is an inherent complication related to the extent of the surgery and time required for surgery; however, a series of measures can be taken to prevent this complication $^{22,24}$. Preventative measures include the use, whenever possible, of trocars of smaller diameter, avoiding extreme manipulation of trocars, introducing trocars with a Z-incision technique, and preventing direct communication between the skin and the fas$\mathrm{cia}^{22,24}$. These techniques are not endorced by other authors, such as Hodgall et al., who instead suggest avoiding the direct introduction of the trocar into the umbilical scar ${ }^{17}$. At the end of the procedure, the patient must be well relaxed, the abdominal gas should be withdrawn slowly, and trocars must be removed under direct visualization. The wound must be touched carefully. Adequate closure of the aponeurosis for wounds larger than $10 \mathrm{~mm}$ must always be accomplished $^{3,4,22}$. The closure of the aponeurosis in a wound of $5 \mathrm{~mm}$ or greater is recommended for the pediatric population ${ }^{9}$.

Some authors attribute the development post-laparoscopic IH to the diameter of the fascial defect, whether from the use of trocars of larger diameters $^{25}$, from the dilatation of the fascial defect, by the use of clippers or staplers $^{20}$, or the use of "fascial screws" 21. However, we believe another important cause of post-laparoscopic IH is the failure of the surgeon to adequately close the defect in the aponeurosis, either because of delegating this function to the less experienced members of the team or because of not obtaining adequate display of the aponeurosis, because to do so, enlarging the incision of the skin would be required. One of the cases reported (case 1) developed $\mathrm{IH}$ in the $10^{\text {th }} \mathrm{PD}$, and certainly, flawed technique was involved. We should not forget that the advantages of the video-assisted laparoscopic procedure are compromised by the development of the $\mathrm{IH}$, requiring the patient to undergo the discomfort and risk of a second surgical intervention. Therefore, we consider the closure of the aponeurosis to be a basic step in the video-assisted laparoscopic procedure.

\section{RESUMO}

TEIXEIRA F e col. - Hérnia incisional no sítio de inserção do trocar de laparoscopia. Rev. Hosp. Clín. Fac. Med. S. Paulo 58(4):219-222, 2003.

As operações por via de acesso videolaparoscópica proporcionam, de um modo geral, uma série de vantagens refletidas em recuperação mais rápida no pós-operatório. Dentre as causas de morbidade da ferida cirúrgica no acesso laparoscópico, a hérnia incisional no sítio de inserção do trocar de laparoscopia é considerada incomum, podendo não ser facilmente diagnosticada.

Em nosso serviço duas pacientes submetidas a colecistectomia laparoscópica evoluíram com hérnias incisionais. Apresentamos os relatos dos casos e revisão da literatura.

DESCRITORES: Hérnia. Hérnia Incisional. Laparoscopia. Colecistectomia. Colelitíase. 
1. DUBOIS F, ICARD P,BERTHELOT G et al. - Coelioscopic cholecystectomy. Preliminary report of 36 cases. Ann Surg 1990; 211(1): 60-62.

2. SOPER N, BARTEAU J, CLAYMAN R et al. - Comparision of early postoperative results for laparoscopy versus standard open cholecystectomy. Surg Gynaecol Obstet 1992; 174: 114-118.

3. AZURIN D, LESLIEG, ARROYO L et al. - Trocar site herniation following laparoscopy cholecystectomy and the significance of na incidental preexisting umbilical hernia. Am Surg 1995; 61: $718-720$.

4. FERNANDEZ-REPRESA J, MAYOL J, GARCIA-AGUILAR J et al. - Risks of the minimal access approach for laparoscopic surgery: Multivariate analysis of morbity related to umbilical trocar insertion. World J Surg 1997; 21: 529-533.

5. NAKAJIMA K, MASAFUMI W, HISAYOSHI $\mathrm{K}$ et al. - Revision laparoscopy for incarcerated hernia at a $5-\mathrm{mm}$ trocar site following pediatric laparoscopic surgery. Surg Laparosc Endosc 1999; 9(4): 294-295.

6. BOURKE J - Small-intestinal obstruction from a Richter's hernia at the site of insertion of a laparoscope. BMJ 1977; 26: 13931394.

7. WILliamS M, FLOWERS S, FENOGLIO M et al.- Richter Hernia: A rare complicatiom of laparoscopy. Surg Laparosc Endosc 1995; 5: 419-421.

8. CHANG F, LEE C, SOONG Y - Extra-umbilical incisional hernias after operative laparoscopy: prevention and management. Int J Gynecol Obstet 1994; 45: 161-162.

9. JONES D, CALLERY M, SOPER N - Strangulated incisional hernia at trocart site. Surg Laparosc Endosc 1996; 6(2): 152154 .

10. PATTERSON M, WALTERS D, BROWDER W - Postoperative bowel obstruction following laparocopic surgery. Am Surg 1993; 59: 656-657. 73(2):265-289.

11. BISHOP H, HALPIN T- Dehiscence following laparoscopy.Report of an unusual complication. Am J Obstet Gynecol 1973; 116(4):585-586.

12. TSANG S, NORMAND R, KARLIN R- Small Bowel Obstruction: A morbid complication after laparoscopic herniorrhaphy. Am Surg 1994; 60(5): 332-334.

13. KREUTZER E, LERNER S, KAHAN N et al.- Laparoscopic treatment of small-bowel obstruction following laparoscopic lymphadenectomy. Urology 1994; 44 (5): 768-770.

14. HENDRICKSE C, EVANS D - Intestinal obstruction following laparoscopic inguinal hernia repair. B J Surg 1993; 80: 1432.

15. MCMILLAN J, WATT I - Herniation at the site of cannula insertion after laparoscopic cholecistectomy. Br J Surg 1993; 80: 915.

16. HORGAN P, O'CONNEL L - Subumbilical hernia following laparoscopic cholecistectomy. Br J Surg 1993; 80: 1595
17. HOGDALL C, ROOSEN J - Incarcerated hernia follwing laparoscopy. Acta Obstet Gynecol Scand 1987; 66: 735-736.

18. SCHIFF I, NAFTOLIN F - Small bowel incarceration after uncomplicated laparoscopy. Obstet Gynecol 1974; 43(5): 674675.

19. REISSMAN P, SHILONI.E, GOFRIT O et al. - Incarcerated hernia in a lateral trocar site postoperative complicatiom of laparoscopic surgery. Eur J Surg 1994; 160: 191-192.

20. LAJER H, WIDECRANTZ S, HEISTERBRG L - Hernias in trocar ports following abdominal laparoscopy. A Review. Acta Obset Gynecol Scand 1997; 76: 389-393.

21. BOIKE G, MILLER C, SPIRTOS N et al. - Incisional bowel herniations after operative laparoscopy: A series of nineteen cases and review of literature. Am J Obstet Gynecol 1995; 172(6): 1728-1733.

22. RABINERSON D, AVRECH O, NERI A et al.- Incisional Hernias after laparoscopy.CME Review Article. Obstet Gynecol Survey 1997; 52(11): 701-703.

23. FEAR R - Laparoscopy: A valuable aid in gynecologic diagnosis. Obstet Gynecol 1968; 31: 297.

24. KADAR N, REICH H, LIU C et al.- Incisional hernias after major laparoscopic gynecologic procedures. Am J Obstet Gynecol 1993; 168: 1493-1495.

25. MONTZ F, HOLSCHNEIDER C, MUNRO G - Incisional hernia following laparoscopy: A Survey of the American Association of Gynecologic Laparoscopists. Obstet Gynecol 1994; 84: 881-884.

26. NADLER R, MCDOUGALL E, BULLOCK A et al.- Fascial closure of laparoscopic port sites: A new technique. Urology 1995; 45(6): 1046-1048.

27. REICH H, CLARKE H, SEKEL L - A simple method for ligating with straight and curved needles in operative laparoscopy. Obstet Gynecol 1992; 79: 143-147.

28. ELASHRY O, NAKADA S, WOLF L et al. - Comparative clinical study of port-closure techniques following laparoscopic surgery. J Am Coll Surg 1996; 183: 335-344.

29. BERGUER R - A technique for full thickness closure of laparoscopic trocar sites. J Am Coll Surg 1995; 180:227-228.

30. WEILAND D, CHEUNG P, HEILBRON J - An Inexpensive, quick, and easily learned technique for closure of abdominal trocar wounds after laparoscopy. J Am Coll Surg 1995;180: 225-227.

31. CRIST D, GADACZ T - Complications of laparoscopic surgery. Surg Clin North Am 1993; 73(2): 265-289.

32. IKARD R - Combinig laparoscopic cholecystectomy and (peri) umbilical herniorrhaphy. Am Surg 1995; 4: 304-305.

33. WHITELEY M (Letter) - Herniation at the site of cannula insertion after laparoscopic cholecystectomy. Br J Surg 1993; 80(11): 1488 . 